\title{
Depth of almost strictly sign regular matrices (CMMSE 2021)
}

Pedro Alonso $^{1}$, Jorge Jiménez ${ }^{1}$, Juan Manuel Peña ${ }^{2}$, and María Luisa Serrano ${ }^{1}$

${ }^{1}$ University of Oviedo

${ }^{2}$ University of Zaragoza

November 23, 2021

\begin{abstract}
The concept of depth of an almost strictly sign regular matrix is introduced and used to simplify some algorithmic characterizations of these matrices.
\end{abstract}

\section{Hosted file}

DEPTH_ASSR (MMAS_16112021).pdf available at https://authorea.com/users/447560/articles/546527depth-of-almost-strictly-sign-regular-matrices-cmmse-2021 